DOI:10.17516/1997-1370-0726

УДК 159.923.2

\title{
Self-Determination as a Psychological Resource of Teacher's Personal and Professional Development
}

\author{
Elena Yu. Pochtaryova* and Nataliya N. Vasyagina \\ Ural State Pedagogical University \\ Ekaterinburg, Russian Federation
}

Received 02.12.2019, received in revised form 12.01.2021, accepted 09.03.2021

\begin{abstract}
Self-determination in the context of a teacher's personal and professional development has become a relevant research subject due to the humanistic and personoriented education focused on the development of an active and self-identifying personality. The aim of the paper is the psychological analysis of motivational self-determination processes as a subjective foundation for the personal and professional development of a teacher. Based on the modern psychological approaches to the self-determination phenomenon, the paper discusses the integrative mechanisms and internalization factors that determine the satisfaction with the activity and productivity of a teacher. The authors present their reasons in favour of a conceptual model of personal and professional characteristics of a teacher's self-determination. They argue that self-determination and associated concepts of autonomy, internally motivated activity, developing learning environment, dialogue, facilitation, persistence, and involvement identify the essence of personal and professional development of a teacher as a psychological resource system. The authors conclude that the axiological creative content of self-determination processes integrates the diverse types of motivational tendencies in the pedagogical activity, highlighting the consistency and coherence of a teacher's personal and professional development.
\end{abstract}

Keywords: self-determination, agency, pedagogical activity, internalization, basic psychological needs, personal development orientations of education.

Research areas: psychology, pedagogy.

Citation: Pochtaryova, E. Yu., Vasyagina, N.N. (2021). Self-determination as a psychological resource of teacher's personal and professional development. J. Sib. Fed. Univ. Humanit. Soc. Sci., 14(3), $351-$ 362. DOI: 10.17516/1997-1370-0726.

\footnotetext{
(C) Siberian Federal University. All rights reserved

* Corresponding author E-mail address: sshsa@mail.ru

ORCID: 0000-0002-9259-6336 (Pochtaryova); 0000-0003-3899-3768 (Vasyagina)
} 


\title{
Самодетерминация как психологический ресурс личностно-профессионального развития педагога
}

\author{
Е.Ю. Почтарева, Н.Н. Васягина \\ Уральский государственный педагогический университет \\ Российская Федерация, Екатеринбург
}

\begin{abstract}
Аннотация. Актуальность изучения самодетерминации в контексте личностнопрофессионального развития педагога обусловлена гуманистической личностноориентированной направленностью образования на становление активной и самоопределяющейся личности. Целью статьи является анализ психологических закономерностей мотивационных процессов самодетерминации как субъектного основания личностно-профессионального развития педагога. На основе современных психологических подходов к самодетерминации рассматриваются интегративные механизмы и факторы интернализации, обусловливающие удовлетворенность деятельностью и продуктивность педагога. Дается авторское обоснование концептуальной модели личностно-профессиональных характеристик самодетерминации педагога. Показано, что самодетерминация и связанные с ней понятия автономии, внутренней мотивации деятельности, развивающей образовательной среды, диалога, фасилитации, настойчивости, увлеченности определяют сущность личностно-профессионального развития педагога как психологической ресурсной системы. Авторы делают вывод о том, что созидательнотворческое аксиологическое содержание процессов самодетерминации интегрирует разнообразные типы мотивационных тенденций педагогической деятельности, что определяет целостность и согласованность личностно-профессионального развития педагога.
\end{abstract}

Ключевые слова: самодетерминация, субъектность, педагогическая деятельность, интернализация, базовые психологические потребности, личностно-развивающие ориентиры образования.

Научные специальности: 19.00.00 - психологические науки; 13.00.00 - педагогические науки.

\section{Введение в проблему исследования}

В условиях динамичных социокультурных изменений актуальным становится исследование феноменов, раскрывающих мотивационный потенциал личности, интерес к которому пронизывает в настоящее время все сферы общественной жизни, в том числе в образовании реализуется посредством образовательного выбора, направленного на развитие ресурсов субъектов образовательного процесса.

Ведущим целевым ориентиром становится отношение к личности как к главному явлению культуры, воплощающему гуманизирующее мировоззрение образования. Гу- манистические личностно-ориентированные ценности и смыслы определяют ключевую роль мотивационной сферы в реализации процессов саморегуляции, самовыражения, самоосуществления личности.

Проблемы образовательного процесса, с которыми сталкивается в настоящее время профессиональное педагогическое сообщество, показывают, что именно развитие мотивационной сферы педагога должно стать приоритетным ориентиром образования и, в частности, фокусировать личностнопрофессиональное развитие педагога, которое раскрывает ресурсообразующие и рискообразующие потенции в совокупности 
характерных психологических особенностей учительства как профессиональной группы (Mitina, 2018). Продуктивность педагога во многом зависит от готовности к активной преобразующей деятельности, потребности инициировать собственное развитие, то есть самодетерминации - конструкта, объясняющего способность к самоопределению собственной активности.

Самодетерминация как мотивационное основание педагогической деятельности, несмотря на широкое отражение проблематики детерминант профессиональной самореализации педагога в теоретических и прикладных исследованиях, остается еще мало изученной. Таким образом, важность изучения развивающих характеристик самодетерминации обусловлена необходимостью внедрения в практику образования психологических инструментов личностнопрофессионального развития педагога.

\section{Проблемное поле \\ психологических исследований самодетерминации педагога в условиях современного образования}

Гуманистическое целеполагание трансформирует ценностные установки образования, определяя переход от функциональноролевых, дисциплинарно-обучающих моделей к проектированию личностноразвивающей образовательной среды, инициирующей становление активной позиции личности как субъекта образовательных отношений, что интегрирует в образовательный дискурс феномен самодетерминации.

Осмысление образовательного результата с точки зрения субъектности позволяет рассматривать педагогический процесс в обусловленности личностного и профессионального аспектов развития педагога, инновационные представления о котором связаны, в первую очередь, с личностными факторами профессионально важных качеств педагога. С этих позиций ресурсное поле профессионального развития проявляет себя в жизнетворчестве как осуществлении личностного потенциала, определяющего эффективность функционирования субъекта деятельности (Petrova, Kozlova, 2018).

Субъект-субъектные целевые ориентиры определяют сущность педагогической деятельности как профессиональной активности, утверждающей самоопределение, самоуправление и самореализацию личности (Mitina, 2018). В этих условиях единство личностного и профессионального самоопределения выступает смыслообразующим компонентом в аспекте трансспективного развития субъекта социально-профессиональной ситуации жизнедеятельности (Zeer, Symaniuk, 2019).

В мотивационном подходе Э. Деси и Р. Райана понимание самодетерминации личности связано с осуществлением выбора направления собственной активности, которая раскрывает особенности саморегуляции поведения на основе удовлетворенности базовых психологических потребностей в автономии, компетентности, связанности. В качестве эмпирического критерия самодетерминированности поведения выступает гибкость взаимодействия личности с социальной средой, которая становится возможной в осуществлении мотивационной динамики процессов автономии и контроля как воплощения интересов, ценностей и способностей личности (Ryan, Deci, 2000).

Д.А. Леонтьев обосновывает представление о самодетерминации как высшей форме саморегуляции, образующей «главный феномен личностной зрелости» и «форму проявления личностного потенциала» (Leont'ev, 2011: 8). Опосредованность процессов самодетерминации ценностным, смысловым и духовным содержанием сознания обусловливает рефлексивное осмысление деятельности как способности детерминировать обстоятельства, ситуации, события жизнедеятельности и благодаря этому осуществлять деятельность в относительной свободе от заданных внешних и внутренних условий (Leont'ev, 2011).

Мотивационные процессы, выражающие устремления, склонности, предпочтения личности, выделяют индивидуально-значимую ценность внутренних аутентичных детерми- 
нант, побуждающих активность личности. И в то же время важная развивающая роль принадлежит образовательной среде в том случае, если она поддерживает искренность, открытость и способствует развивающим коммуникациям педагога и обучающегося.

Методологической предпосылкой развития самодетерминации личности в образовательном процессе служит понятие среды Э. Деси, Р. Райана, психологический смысл которого состоит в том, что среда «... питает врожденный человеческий потенциал, определяющий рост, интеграцию и здоровье» (Ryan, Deci, 2000: 74). Социальное окружение создает условия для становления внутренней мотивации, поддерживая направленность личности на автономию, предоставляя структуру организации активности и сохраняя включенность в ситуации совместной деятельности (Ryan et al., 1995).

Вместе с тем, наличие проактивной тенденции к освоению социальной среды побуждает личность к усвоению ценностей, норм поведения, культурных практик таким образом, что личность естественным образом вовлекается в активность, которая предполагает удовлетворение базовых психологических потребностей. Поэтому феноменологическое содержание самодетерминации личности раскрывается в совокупности субъективных и объективных факторов, формирующих индивидуальнопсихологические и социально-средовые взаимосвязи между атрибутивными свойствами личности, ситуационной динамикой среды, а также опытом удовлетворения базовых психологических потребностей в автономии, компетентности и связанности (Ryan et al., 2019).

Смена содержания и форм образовательных отношений обусловливает возможность реализации педагогических стратегий, направленных на фасилитацию интернальности поведения, коммуникативной инициативы, познавательной активности, самостоятельности выбора, когда достижение учебных результатов является средством, а не целью образования. Личностно-развивающие ориентиры педа- гогической деятельности порождают многовариантность, дифференциацию, элективность, интегрированность образовательной среды. Социально-психологический контекст образовательного процесса обусловливает нацеленность личностнопрофессионального развития педагога на создание оптимальных условий для адаптации личности обучающегося.

Между тем глобальным противоречием образования в настоящее время является противопоставление смыслополагающих ориентиров, которые предполагают, с одной стороны, целостное развитие и профессиональную самоактуализацию педагога, a с другой - направленность педагогической деятельности на обеспечение внешне нормативных показателей.

Так, Р. Куэвас и др. приводят доводы о том, что система образования в большей степени способствует тому, что педагоги стремятся задействовать в образовательном процессе стратегии, основанные на внешнем контроле в силу того, что педагогическая эффективность оценивается по внешним оценкам результатов успеваемости обучающихся (Cuevas et al., 2018). Также М.Ф. Линч, Н. Салихова, анализируя проблемы самодетерминации в образовании, отмечают фрагментарность восприятия педагогами базовых психологических потребностей с точки зрения здорового и продуктивного развития личности ребенка в образовательной среде. Учителя в большей степени стремятся задействовать образовательные практики, основанные на потребностях в связанности и компетентности, тогда как потребность в автономии кажется им менее значимой (Lynch, Salikhova, 2016).

Однако исследования мотивации и развития личности в образовании обнаруживают выраженную положительную связь самодетерминации педагогов с высокими академическими результатами и благополучием их учеников, утверждая ценность автономных ориентаций мотивации для продуктивного осуществления образовательного процесса (Niemiec, Ryan, 2009). 


\section{Ценности и смыслы как побудительное основание самодетерминации педагога}

Образовательная ситуация задает особые требования к мотивационносмысловой компоненте педагогической деятельности как одному из главных параметров образования, побуждая педагога не просто соответствовать быстрым изменениям, но и активно воздействовать на них, что делает проблематику развития личностно-профессиональных средств самодетерминации интересной и актуальной по-новому.

Конструкт самодетерминации коренным образом меняет содержательноаксиологический контекст образования, определяя многофакторность педагогической деятельности, которая предстает как динамическое полисубъектное взаимодействие, обусловливающее созидательный процесс становления ценностных ориентиров личности. Педагогический процесс в мотивационном пространстве самодетерминации образует диалог в постоянно развивающейся системе «педагог - обучающийся», в которой личность выстраивает собственный опыт отношений с миром.

Субъект-субъектная ориентация педагогического взаимодействия обусловливает рефлексию и осознание профессиональной активности педагога, когда образовательный процесс реализуется преимущественно в форме сотрудничества с позиций открытости в отношении субъективной реальности собственной психики, внутреннего мира других людей и обеспечивает осуществление процессов интернализации, в которых раскрывается личностный потенциал обучающегося и педагога.

Концепция интернализации Э. Деси, Р. Райана обосновывает эвристическое представление о самодетерминации как многомерной модели автономной (интернальной, интегрированной, идентифицированной) и контролируемой (интроецированной, экстернальной, амотивации) типами регуляции, раскрывающими «разнообразные виды мотивации, основанные на различных «драйверах» или мотивационных силах, лежащих в основе поведения человека» (Rigby, Ryan, 2018: 136).

При этом современное аксиологическое пространство образования, обусловливая многообразие связей, в которые вовлечен педагог, определяет разнообразные внешние и внутренние факторы детерминационных процессов развития субъектного опыта личности, в котором широкий диапазон возможностей выбора направлений жизнеосуществления сопряжен с «экзистенциональным вызовом» (Sheldon, 2016: 11) в условиях дезинтеграции социокультурных оснований смыслов и ценностей поведения личности.

Противоречивые и разнонаправленные тенденции культурных, духовных, межличностных, социально-профессиональных ориентиров, которые проявляются на уровне как индивидуального, так и группового субъекта, определяют смыслополагание образования как фундаментальной способности личности к проектированию собственного жизненного пути, направленной на становление и развитие умений управления своей деятельности, организации активности, саморегуляции психических состояний. В связи с этим объяснительные механизмы континуума интернализации позволяют переосмыслить мотивационный контекст личностноориентированных процессов самодетерминации, раскрывая интегративную природу ценностно-смысловых отношений взаимодействия субъекта с социальной средой.

Типы внешней регуляции - интроецирование, идентифицирование, интегрирование, - наряду с экстернальным (внешним) регулированием, отражают различную степень принятия ценностей деятельности, раскрывающих стилевые особенности качества мотивации «... от менее автономных до более автономных», которые имеют «функционально разные катализаторы, сопутствующие факторы и последствия» (Ryan, Deci, 2017: 20-21). Психологическое содержание интегрированной регуляции наиболее близко внутренней мотивации, поскольку в обоих случаях деятельность со- 
провождается ощущением добровольного выбора. Тогда как сущностным различием интегрированной и внутренней мотивации является отношение к ценности деятельности, которая при внутренней мотивации раскрывает интерес к деятельности как таковой, а в случае интегрированной мотивации ценность деятельности, привнесенная извне, становится усвоенным и принятым регулятором активности личности (Sheldon et al., 2017).

Субъект-субъектные

ориентиры

личностно-профессионального развития педагога актуализируют стилеобразующую функцию процессов интернализации, обусловливая понимание педагогического процесса как интеграции субъективных вариативов педагогического взаимодействия, направленных на то, чтобы помочь личности ребенка наиболее полно использовать предоставленные возможности образования, а также адаптировать индивидуальнопсихологические свойства к заданным извне школьным условиям. В этом ракурсе личностно-профессиональное развитие педагога предстает как психологическая система самодетерминации, смысловые ориентиры которой обусловливают гибкость саморегуляции как мотивационного основания субъектного потенциала педагогического процесса в многообразии индивидуально-психологических и социокультурных особенностей субъектов образования.

Сообразно процессам интернализации самодетерминация приобретает смыслообразующее значение, определяя ценность профессионального труда для педагога, обусловливающего продуктивность педагогического взаимодействия, в котором осуществляется поддержка самоэффективности и вовлеченности обучающихся (Reeve, Lee, 2014), возрастных особенностей автономной мотивации учебной деятельности (Gillet et al., 2012), внутренних учебных целей к достижению академических результатов (Renaud-Dube et al., 2015).

Таким образом, аксиологические характеристики личностно-профессионального развития педагога, воплощая субъект- субъектные ценности образования, определяют направленность педагогического процесса на становление автономии и самодетерминации, в которых интернализация внешнего плана поведения определяет внутриличностный план субъективного осмысления педагогом ценностей развития личности в образовании, обусловливая интеграцию мотивационных ориентаций регуляции педагогической деятельности как в ситуативных проявлениях, так и в глобальных основаниях жизнедеятельности.

\section{Интеграция личностного \\ и профессионального как среда развития самодетерминации педагога: сущность и содержание}

Содержательно и функционально способность педагога к самодетерминации находит свое осуществление в образовательной реальности индивидуального опыта, погружаясь в который педагог решает задачи психического, личностного, социального, профессионального развития. Субъектные характеристики личностнопрофессионального развития, наполняя аутентичным содержанием самоосуществление педагога как реализации самостоятельного осознанного выбора, опосредуют динамическую целостность профессионально-педагогической социализации, индивидуализации и адаптации, обусловливая психологическую востребованность самодетерминации в сфере гуманизации образования.

Личностно-профессиональные характеристики самодетерминации педагога образуют психологическую ресурсную систему, концептуальная модель которой, как мы полагаем, можно быть определена следующим образом (рис. 1).

Вариативность мотивационного стиля. Психологическая природа мотивационных процессов раскрывается в континуальном пространстве автономной и контролируемой ориентаций педагогической деятельности, обусловливающем развивающий потенциал образовательных отношений, в многообразии эмоционально- 


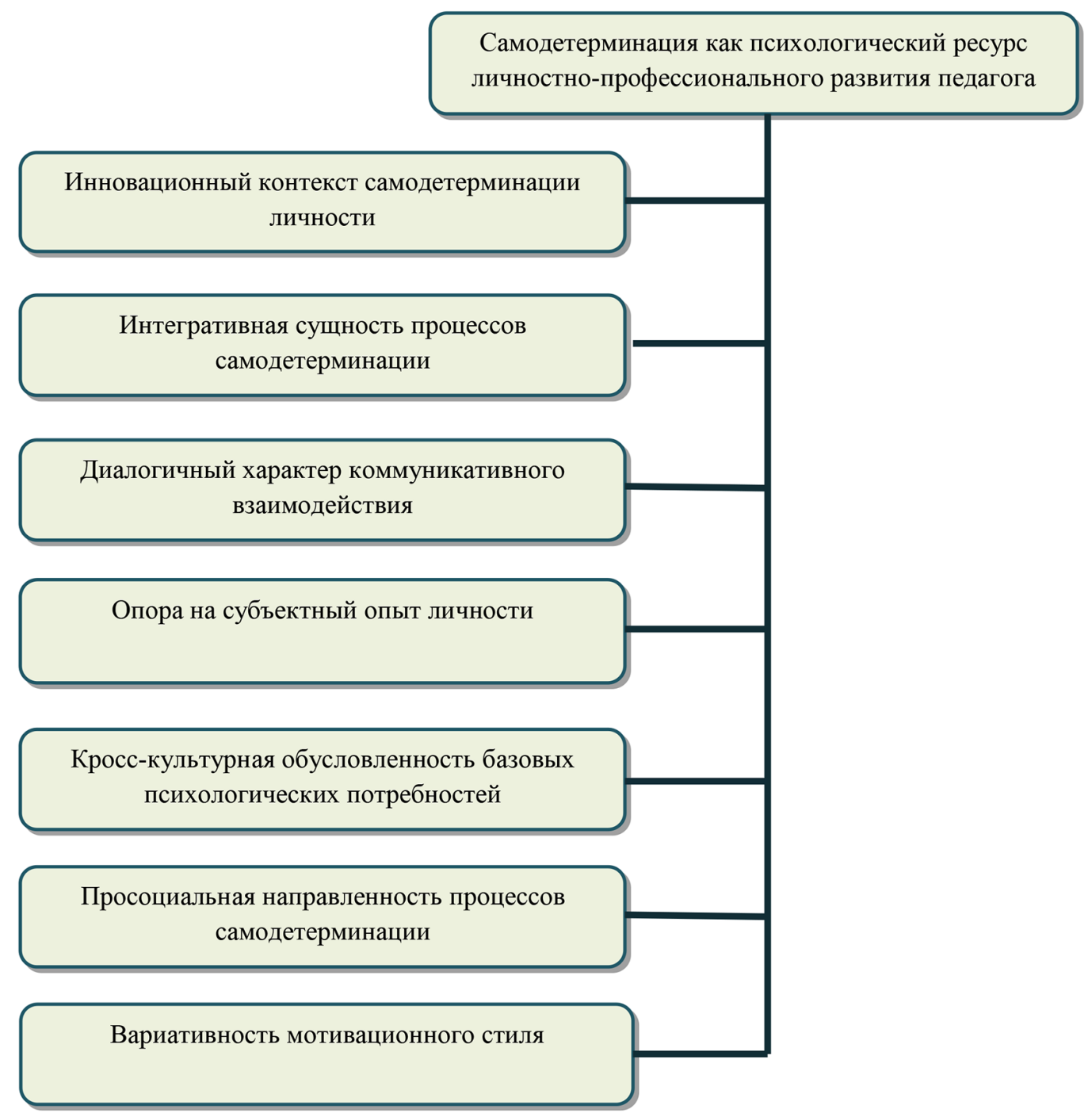

Рис. 1. Концептуальная модель самодетерминации как психологической ресурсной системы личностно-профессионального развития педагога

Fig. 1. Conceptual model of self-determination as a psychological resource system of personal and professional development of a teacher

социальных, индивидуально-возрастных, ин теллектуально - познавательных, ценностно-смысловых, волевых свойств личности, адаптивность которых реализует дидактические, пространственно-временные, психолого-педагогические, социокультурные, инструментально-методические средства образования. Вариативность регуляции педагогической деятельности обеспечивает поддержку восприятия выбора, чувства со- причастности, удовлетворенности учебой, настойчивости обучающихся и, как следствие, более высокого качества образовательного процесса (Vansteenkiste, Ryan, 2013).

Просоциальная направленность процессов самодетерминации. Направленность педагога к преобразующему взаимодействию способствует осознанности и рефлексивности как самовыражению личности в совместной деятельности. Внутренне 
мотивированная активность педагога оптимизирует интернализацию ценностей самоопределения личности обучающегося (Assoret al., 2018). Особое внимание исследователи обращают на основополагающее отличие понятий автономии и независимости, обосновывая контролируемую природу независимости как характеристики, выражающей ориентацию на целевые ориентиры, которые не способствуют подлинности устремлений личности (Ryan, Deci, 2017). В исследованиях также раскрывается взаимовлияние просоциального поведения, осмысленности деятельности и субъективного восприятия удовлетворенности базовых психологических потребностей в автономии, компетентности и связанности (Martela, Ryan, 2016). Контролирующее педагогическое взаимодействие выявляет связь с проблемным и асоциальным поведением школьников (Heinet al., 2015).

Кросс-культурная обусловленность базовых психологических потребностей. Универсальные основания базовых потребностей в автономии, компетентности и связанности обусловливают субъектсубъектные отношения педагога и обучающегося как смысловой общности разнообразия мотивационных проявлений участников образовательного процесса, социокультурная специфичность осуществления которых раскрывает широкий спектр возможностей образовательных траекторий в целях развития способностей и направленности личности. Мультикультурный характер процессов самодетерминации позволяет прогнозировать мотивационные результаты самореализации представителей ценностей разных культурных групп, как индивидуалистических, так и коллективистических (Kaplan, Madjar, 2017).

Опора на субъектный опыт личности. Осуществление опыта автономии находит свое воплощение с раннего детства в вовлеченности ребенка в эмоциональные и телесные взаимосвязи со взрослыми, взаимодействии с игрушками и играми, способствующими «... оптимальному развитию интернализации и благополучию малышей» (Côté-Lecaldareetal., 2016: 823). Субъ- ектное наполнение образовательного дискурса воплощает личностно-развивающий потенциал самодетерминации, раскрывающий мотивационный потенциал педагогической деятельности как условия смысложизненной реализации личности. Становление психологического пространства субъектного опыта самодетерминации реализуется в социальных практиках инициативы и самостоятельности активности личности в дошкольном возрасте, адаптации в формальных и неформальных группах общения в школьный период развития, а также профессионализации и индивидуализации в последующие возрастные этапы развития личности (Ratelle, Duchesne, 2014).

Диалогичный характер коммуникативного взаимодействия. Субъект-субъектные процессы самодетерминации обусловливают развивающие эффекты педагогического взаимодействия, образуя условия для «... полноценно функционирующей личности как существа, обладающего подлинным осознанием и способностями к автономии, интеграции и связи с другими» (Ryan, 2019: 125). В такой образовательной среде психологические процессы педагогической деятельности раскрываются в реализации постоянно развивающейся системы способностей личности педагога (Mazilov, Slepko,2019). В этом случае опыт поддержки базовых потребностей в автономии, компетентности и связанности детерминирует социальные навыки и оптимальное функционирование в межличностной сфере (Costaetal., 2015), создающей безопасность, доверительность, положительные эмоции и удовлетворенность образовательным процессом (Kaplan, Assor, 2012).

Интегративная сущность процессов самодетерминации. Интеграционные процессы предопределяют аксиологическую трансформацию педагогической деятельности, в которой наряду с ценностью стабильности профессиональной позиции все большее значение приобретает динамический статус педагога, обусловленный устремленностью к развитию опыта в разнообразных ситуациях взаимодействия. В русле развивающей и развивающейся реальности 
образования интеграция постоянного и изменчивого обусловливает продуктивную самореализацию, когда педагог как субъект социокультурного пространства созидает личностные смыслы педагогического труда. Такой образовательный процесс вовлекает естественные стремления обучающегося к инициативе и любознательности в исследовании окружающего мира (Ryan, Niemiec, 2009), побуждающего подлинное волеизъявление личности, а не осуществление активности под воздействием процессов самоконтроля, внутреннего и внешнего давления (Vansteenkiste et al., 2012).

Инновационный контекст самодетерминации личности. Самодетерминация как неотъемлемое свойство внутренней мотивации непрерывного образования определяет творческий поиск психологометодических средств, дидактического инструментария, педагогических технологий, нацеленных на создание условий для осуществления рефлексивного способа учительского труда и преодоления дисфункциональных аспектов образовательного процесса. Трансформация представлений учителей о целесообразности осуществления базовых психологических потребностей в образовательной среде детерминирует направленность педагога к внедрению инновационных образовательных практик (Gorozidis, Papaioannou, 2014), в которых поддержка интеграции и самореализации обучающегося ведет к развитию и обогащению личностно-профессиональных характеристик педагога, обусловливает благополучие и продуктивность субъектов образовательного процесса.

Самодетерминация, таким образом, предстает как субъектное основание личностно-профессиональных механизмов и факторов регуляторных процессов педагогической деятельности, содержательные стороны которых раскрывают потенциал самоосуществления личности в образовательной среде. Сущностные различия между автономным и контролируемым типами мотивации подчеркивают важность профессиональной позиции педагога как личностной предпосылки удовлетворения базовых психологических потребностей. Претворяя экзистенциональную природу субъектности, самодетерминация позволяет рассматривать многоплановость психологических, социальных, культурных, профессиональных качеств педагога, определяющих динамические особенности мотивационных ориентаций педагогического процесса, субъективная значимость которых создает мотивирующую среду образовательных отношений как развивающих общностей, в которых самодетерминация предстает как интегрирующий способ осуществления личностно-профессионального развития педагога.

\section{Заключение}

Анализ феноменов мотивации, саморегуляции, субъектности педагога позволяет сделать вывод о фундаментальном значении включения в предметное содержание исследований в образовании имманентных психологических закономерностей детерминации личности, в русле которых конструкты автономии, самодетерминации и базовых психологических потребностей приобретают инвариантный статус личностно-профессионального развития педагога как целостного явления.

Самодетерминация педагога, будучи, с одной стороны, мотивационным образованием, а с другой - регуляторным механизмом педагогической деятельности, поновому раскрывает субъектный потенциал личностно-профессионального развития педагога, а именно как переживания удовлетворенности, эмоционально-ценностной вовлеченности, смысловой наполненности в условиях совместной деятельности педагога и обучающегося.

Осуществление самодетерминации в образовательной среде становится возможным посредством реализации стратегии интернализации как аксеологического основания личностно-профессионального развития педагога, обеспечивающего концептуальное решение проблемы детерминант оптимальных качественных изменений мотивации на основе диалектической взаимообусловленности индивидуально- 
психологических особенностей саморегуляции педагога и средовых характеристик образовательной поддержки психологических потребностей в автономии, компетентности и связанности.

Говоря о ресурсных возможностях самодетерминации в контексте личностнопрофессионального развития педагога, следует отметить, что дискуссионным остается вопрос о психолого-методическом обеспечении сопровождения поддержки базовых психологических потребностей как педагога, так и обучающегося, что составляет перспективное направление психологических исследований мотивации и раз- вития субъектности личности средствами образовательного процесса.

Таким образом, гуманистическое содержание самодетерминации раскрывает сущность личностно-профессионального развития как ценностного креативного отношения к образовательному процессу, наполняющему педагогическое взаимодействие развивающим контекстом, повышая степень открытости педагога, его социально-позитивную эмоциональность, релевантность, согласованность как условия становления активной, свободной, ответственной, самоактуализирующейся личности в образовательной среде.

\section{Список литературы / References}

Assor, A., Feinberg, O., Kanat-Maymon, Y., \& Kaplan, H. (2018). Reducing violence in non-controlling ways: A change program based on self determination theory. In The Journal of Experimental Education, 86(2), 195-213. DOI: 10.1080/00220973.2016.1277336

Costa, S., Ntoumanis, N., \& Bartholomew, K. (2015). Predicting the brighter and darker sides of interpersonal relationships: Does psychological need thwarting matter? In Motivation and Emotion, (39), 11-24. DOI: $10.1007 / \mathrm{s} 11031-014-9427-0$

Côté-Lecaldare, M., Joussemet, M., \& Dufour, S. (2016). How to support toddlers' autonomy: A qualitative study with childcare educators. In Early Education and Development, 27(6), P. 822-840. DOI: 10.1080/10409289.2016.1148482

Cuevas, R., Ntoumanis, N., Fernandez-Bustos, J.G., \& Bartholomew, K. (2018). Does teacher evaluation based on student performance predict motivation, well-being, and ill-being? In Journal of School Psychology, 68, 154-162. DOI: 10.1016/j.jsp.2018.03.005

Gillet, N., Vallerand, R.J., \& Lafrenière, M.-A.K. (2012). Intrinsic and extrinsic school motivation as a function of age: The mediating role of autonomy support. In Social Psychology of Education: An International Journa, (15), 77-95. DOI: 10.1007/s11218-011-9170-2

Gorozidis, G., \& Papaioannou, A. (2014). Teachers' motivation to participate in training and to implement innovations. In Teaching and Teacher Education, (39), 1-11. DOI: 10.1016/j. tate.2013.12.001

Hein, V., Koka, A., \& Hagger, M.S. (2015). Relationships between perceived teachers' controlling behaviour, psychological need thwarting, anger and bullying behaviour in high-school students. In Journal of Adolescence, (42), 103-114. DOI: 10.1016/j.adolescence.2015.04.003

Kaplan, H., \& Assor, A. (2012). Enhancing autonomy-supportive I-Thou dialogue in schools: Conceptualization and socio-emotional effects of an intervention program. In Social Psychology of Education, (15), 251-269. DOI: 10.1007/s11218-012-9178-2

Kaplan, H., \& Madjar, N. (2017). The motivational outcomes of psychological need support among pre-service teachers: Multicultural and self-determination theory perspectives. In Frontiers in Education, (2), 1-14. DOI: 10.3389/feduc.2017.00042

Leont'ev, D.A. (2011). Vvedenie: lichnostnyj potencial kak ob»ekt izucheniya [Introduction: personal potential as object of study]. In Lichnostnyj potencial. Struktura i diagnostika, pod red. D. A. Leont'eva [Personal potential: structure and diagnostic, D. A. Leontiev (ed.)]. Moscow, Smysl, 6-11.

Lynch, M.F., \& Salikhova, N.R. (2016). Teachers' conceptions about the child's developmental needs: a structural analysis. In Mathematics Education Research Journal, (11), 1471-1479. 
Martela, F., \& Ryan, R.M. (2016). Prosocial behavior increases well-being and vitality even without contact with the beneficiary: Causal and behavioral evidence. In Motivation and Emotion, (40), 351-357. DOI: $10.1007 /$ s11031-016-9552-z

Mazilov, V.A. \& Slepko, Yu.N. (2019). Formirovanie pedagogicheskoj odarennosti kak klyuchevoe uslovie povysheniya effektivnosti sovremennoj obrazovatel'noj sistemy [Pedagogical giftedness as a key prerequisite for efficient modern educational system]. In Integraciya obrazovaniya [Integration of Education], 23(1), 37-49. DOI: 10.15507/1991-9468.094.023.201901.037-049

Mitina, L.M. (2018). Lichnostno-professional'noe razvitie uchitelya: strategii, resursy, riski [Personal and professional development of teachers: strategies, resources, risks]. Moscow \& St. Petersburg, NestorIstoriya, $456 \mathrm{p}$.

Niemiec, C.P., \& Ryan, R.M. (2009). Autonomy, competence, and relatedness in the classroom: Applying self-determination theory to educational practice. In Theory and Research in Education, 7(2), $133-144$. DOI: $10.1177 / 1477878509104318$

Petrova, V.N., Kozlova, N.V. (2018). Professional'noe razvitie v menyayushchemsya mire: strategiya zhizneosushchestvleniya [Professional development in changing world: strategy of life implementation]. In Sibirskiy Psikhologicheskiy Zhurnal [Siberian journal of psychology], (70), 59-74. DOI: 10.17223/17267080/70/5

Ratelle, C.F., \& Duchesne, S. (2014). Trajectories of psychological need satisfaction from early to late adolescence as a predictor of adjustment in school. In Contemporary Educational Psychology, (39), 388-400. DOI: 10.1016/j.cedpsych.2014.09.003

Reeve, J., \& Lee, W. (2014). Students' classroom engagement produces longitudinal changes in classroom motivation. In Journal of Educational Psychology, 106(2), 527-540. DOI: 10.1007/s11218-011-9170-2

Renaud-Dube, A., Talbot, D., Taylor, G., \& Guay, F. (2015). The relations between implicit intelligence beliefs, autonomous academic motivation, and school persistence intentions: A mediation model. In Social Psychology of Education: An International Journal, (18), 255-272. DOI: 10.1007/s11218-014-9288-0

Rigby, C.S., \& Ryan, R.M. (2018). Self-determination theory in human resource development: New directions and practical considerations. In Advances in Developing Human Resources, 20(2), 133-147. DOI: $10.1177 / 1523422318756954$

Ryan, R.M., Deci, E.L., \& Grolnick, W.S. (1995). Autonomy, relatedness, and the self: Their relation to development and psychopathology. In Developmental psychopathology: Theory and methods, D. Cicchetti, \& D. J. Cohen (Eds.), (1). New York, Willey - Interscience, 618-655.

Ryan, R.M. \& Deci, E.L. (2000). Self-determination theory and the facilitation of intrinsic motivation, social development and well-being. In American psychologist, 55(1), 68-78. DOI: 10.1037/0003066X.55.1.68

Ryan, R.M., \& Deci, E.L. (2017). Self-Determination Theory: Basic Psychological Needs in Motivation, Development, and Wellness. New York, Guilford Publishing, $756 \mathrm{p}$.

Ryan, R.M., \& Niemiec, C.P. (2009). Self-determination theory in schools of education: Can an empirically supported framework also be critical and liberating? In Theory and Research in Education, 7(2), 263-272. DOI: 10.1177/1477878509104331

Ryan, R.M., Soenens, B., \& Vansteenkiste, M. (2019). Reflections on self-determination theory as an organizing framework for personality psychology: Interfaces, integrations, issues, and unfinished business. In Journal of Personality, 87(1), 115-145. DOI: 10.1111/jopy.12440

Sheldon, K.M. (2016). Vvedenie v teirij samodeterminacii i novye podhody k motivacii rosta [Introduction to the Self-determination Theory and New Approaches to Growth Motivation]. In Sibirskij psihologicheskij zhurnal [Siberian journal of psychology], 62, 7-17. DOI: 10.17223/17267080/62/2

Sheldon, K.M., Osin, E.N., Gordeeva, T.O., Suchkov, D.D., \& Sychev, O.A. (2017). Evaluating the dimensionality of self-determination theory's relative autonomy continuum. In Personality and Social Psychology Bulletin, 43(9), 1215-1238. DOI: 10.1177/0146167217711915

Vansteenkiste, M., Sierens, E., Goossens, L., Soenens, B., Dochy, F., Mouratidis, A., Aelterman, N., Haerens, L, \& Beyers, W. (2012). Identifying configurations of perceived teacher autonomy support and 
structure: Associations with self-regulated learning, motivation and problem behavior. In Learning and Instruction, (22), 431-439. DOI: 10.1016/j.learninstruc.2012.04.002

Vansteenkiste, M., \& Ryan, R.M. (2013). On psychological growth and vulnerability: Basic psychological need satisfaction and need frustration as a unifying principle. In Journal of Psychotherapy Integration, (23), 263-280. DOI: $10.1037 / \mathrm{a} 0032359$

Zeer, E.F., \& Symaniuk, E.E. (2019). Psihologicheskie osobennosti samoopredeleniya lichnosti v postindustrial'nom obshchestve [Personality's self-determination psychological features in the postindustrial society]. In Novoe v psihologo-pedagogicheskih issledovaniyah [New in psychological and pedagogical research], 1(53), 76-83. 